\title{
Design of Rotating Sprinkler with Variable Discharge
}

\author{
Amar B P ${ }^{1}$, G Sai Teja ${ }^{2}$, Venkatesh $E^{3}$, Sandeep $V^{4}$ \\ Vit University, Chennai Campus, India
}

\begin{abstract}
Sprinkler rotors operate by rotating a stream of water over the landscape instead of the mist produced by spray head sprinklers. This allows rotors to be placed farther apart than spray head sprinklers, saving you installation time and money. Rotors are generally designed to rotate in full or partial circles and do not perform with a throw radius of less than 15 feet.The main objective is to vary the discharge and to cover more sprinkling area.
\end{abstract}

\section{Objective}

The objective of this model is to provide sprinkler which provides the variable discharge for every four rotation of the nozzle. For every cycle of four nozzle rotation, stream distance is varied. As for each four rotation radial distance of watering is varied it increases the efficiency of sprinkler to water the lawn area properly.

\section{Methodology}

The model has three nozzles with one of the nozzle can be closed or opened for each four cycle which in turn varies the velocity, when third nozzle is open area for flow is more and hence velocity is low than when it is for nozzle is closed and hence stream will reach less distance than when it is closed.

To vary the number of rotation between the nozzle and arm used for closing the nozzle a gear system with 8:1 rotation of nozzle to arm is used. The rotational motion of gear is transferred to translational motion by the arm. This arm motion will close or open the nozzle.

\section{Design Of Sprinkler}

Sprinkler is designed by using solid works
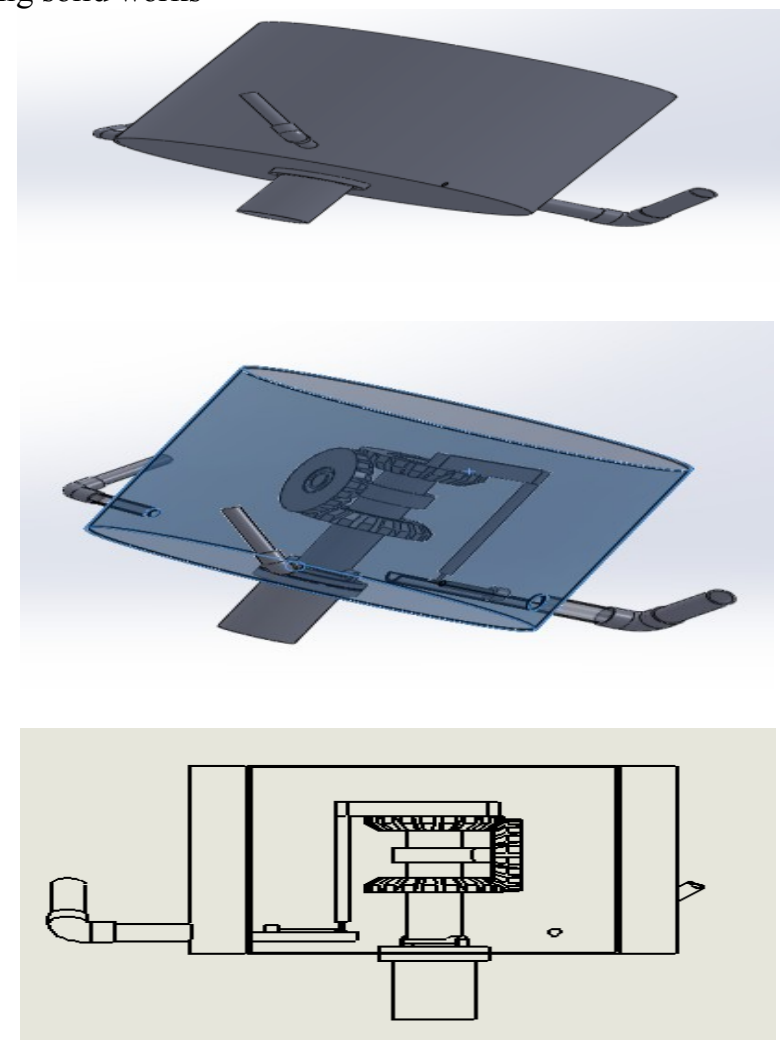


\section{Drawing Details And Working}

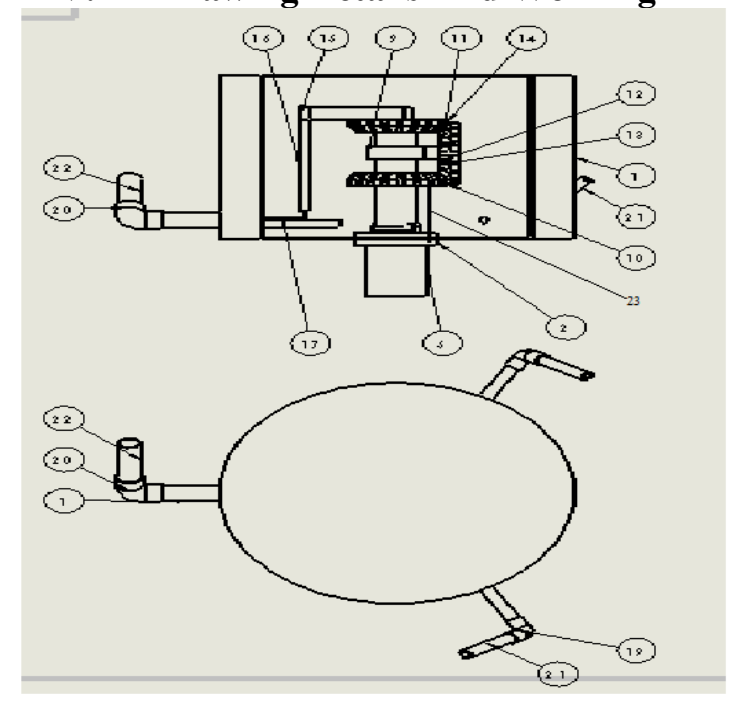

Fig shows the details of base of the sprinkler no. $\mathrm{n} 1$ and $\mathrm{n} 2$ are nozzle with small diameter than $\mathrm{n} 3.5$ is pipe which is used for inlet of flow. 2 are bearing used for free rotation. 2 is attachment with pipe which is used for supporting gear system.17 is piston used for translational motion of the arm. 11 is pivot used for mounting the gear system.10, 12and 14are the gears, 10with rotation of nozzle and 14with 1:8 of 9. Arm 23 is attached with the gear(10) and bearing (2) which makes gear (10) rotation equal to nozzle rotation.And gear (14) is attaches with translational motion arm which consists of arm(15) freely attached to lever arm (16) which is attached with spring and circular block for blocking the nozzle. As 15 rotate with gear 14 it makes the translational motion of arm 16 in the piston system. Suppose 15 is towards the nozzle (n3) than nozzle is closed by the block when gear (14) takes $1: 4^{\text {th }}$ rotation arm is moved away from the nozzle (n3) and loosening the spring and still nozzle (n3) is closed when gear 14 takes rotation beyond $1: 4^{\text {th }}$ to $3: 4^{\text {th }}$ nozzle (n3) is opened and hence for area less velocity and hence less distance is covered. For motion beyond 1:4 $4^{\text {th }}$ to $1: 2$ of gear 13 lever arm (16) with spring is moved away nozzle (n3). And from 1:2 to $3: 4^{\text {th }}$ it moves towards nozzle but still opened but as soon as it is at $3: 4^{\text {th }}$ motion it is just closed and as it moves further for rotation after rotation beyond $3: 4^{\text {th }}$ arm 16 pusses the spring and it closes the nozzle (n3) till next 1:4 $4^{\text {th }}$ of rotation and keeping the cycle repeating. As gear 14 rotation is $1: 8^{\text {th }}$ of nozzle rotation above cycle is repeated for every 8 rotation of nozzle cycle and hence nozzle is closed for 4 rotation of nozzle and opened for 4 rotation of nozzle and hence vary the stream radial distance for every 4 rotation of nozzle. So watering the area efficiently than the conventional sprinklers.

\section{References}

[1]. How to Design and Build a Sprinkler System by Michael A Tenn

[2]. Fluid Mechanics and Hydraulic Machines by R.K.Bansal

[3]. Sprinkler ware house (wiki) 